\title{
Growth Hormone Abnormal, CTCAE
}

National Cancer Institute

\section{Source}

National Cancer Institute. Growth Hormone Abnormal, CT CAE. NCI Thesaurus. Code C143521.

A finding based on laboratory test results that indicate abnormal levels of growth hormone in a biological specimen. 